\title{
PVLab: an innovative and flexible simulation tool to better size photovoltaic units
}

\author{
Z. Ren, S. Jacques, S. Bissey, N. Batut, A. Schellmanns and A. Caldeira \\ University of Tours, GREMAN UMR-CNRS 7347, France \\ 7 avenue Marcel Dassault, 37200 Tours (France) \\ Phone number: +33 2473613 25, e-mail: zheng.ren@univ-tours.fr
}

\begin{abstract}
This paper deals with a new highly modular simulation tool, named as "PVLab" and developed by the GREMAN laboratory, to better size photovoltaic (PV) installations. The programming structure and the physical models implemented within this simulation tool are explained. Several case studies are proposed to highlight the relevance of this new simulation tool. The yearly virtual electrical energy production results of grid-connected PV plants are discussed. In particular, these results are compared with the PVsyst tool ones. PVLab has a high level of flexibility, allowing modifying the physical models and databases (for instance, meteorological data) according the users' needs. This is permitted through the expertise in all the computing steps and particularly, the MATLAB development environment. Controlling the source code gives itself a huge potential in the field of renewable energy applications in comparison with PVsyst which is currently the commercial reference. This point is particularly discussed at the end of the paper.
\end{abstract}

\section{Key words}

PVLab, flexible simulation tool, photovoltaic installation sizing.

\section{Introduction}

Nowadays, photovoltaic (PV) solar energy is widely accepted as a potentially inexhaustible and environmentalfriendly solution [1], [2]. After a remarkable growth over the past decade, it is on the way to become a mature and mainstream source of electricity. The world's cumulative PV installations have impressively surpassed over $100 \mathrm{GW}$ late last year [3]. In Europe, the biggest PV market of the world, the photovoltaic energy represents more than $2 \%$ of the total electricity consumptions [4]. Considering the up-going price of fossil energy and the descending cost of photovoltaic, this number may continue significantly to rise in the foreseeable future.

Study, pre-sizing, simulation and data analysis of PV systems are essential for the development of solar photovoltaic energy. At the moment, PVsyst, which is a system engineering simulation tool, is widely used to perform the entire process of designing a PV system, i.e. from the preliminary assessment of energy efficiency and cost-effectiveness to the development of the project documentation. It has been accepted as a reference by both researchers and engineers for many years. For instance, PVsyst may be suitable for grid-connected, stand-alone, pumping and DC-grid PV system simulations [5]. Another important advantage of PVsyst is its extensive PV-components and meteorological databases. So, it could be helpful to simplify custom PV simulations and improve the accuracy of the results [6]. The shortcoming of PVsyst is that it is not possible to modify the models (i.e. electrical, thermal and optical models) and the databases (in particular, the meteorological databases) implemented in the piece of software.

In this context, the GREMAN laboratory, a research unit funded jointly by the University of Tours (France) and the French National Center for Scientific Research (CNRS), has recently developed a highly flexible PV simulation tool, named as "PVLab", from the MATLAB development environment. This innovative tool allows researchers to personalize various models (i.e. optical, electrical and thermal models) and databases (i.e. PV components such as inverters, solar panels and above all, meteorological databases) to get a better understanding of their impacts on electricity production and efficiency of PV power plants.

The challenges of this paper are to describe the main features of this new modular simulation tool and validate its functioning by comparing the PV production results with PVsyst ones, considering the same input data.

\section{General architecture of PVLab}

The general architecture of PVLab is presented in Fig. 1. In particular, 4 script files, written using the MATLAB environment, act as the core of the simulation tool. The estimation of electricity production of a PV system is usually performed in two stages: the determination of the effective irradiance on the PV unit and the calculation of the power generated under this irradiance level. As can be seen in Fig. 1, these two steps are implemented in the script file named as "Simu.m". In fact, plenty of variables have to be used to determine the two factors mentioned previously. Therefore, the pre-definition of these variables must be done before the calculations. This step is included in 2 script files named as "PVLab.m" and "Interface.m", respectively. To be more specific, the "PVLab.m" script file charges the databases and defines the current work folder, while the "Interface.m" script file recalls the User Interface (UI) and interrogates several parameters which 
are necessary to launch the calculations. At the end of the simulation process of a PV system, a summary report is generated by the script file named as "Report.m". In particular, this report contains most of the important pre- defined parameters and the monthly electrical energy production results.

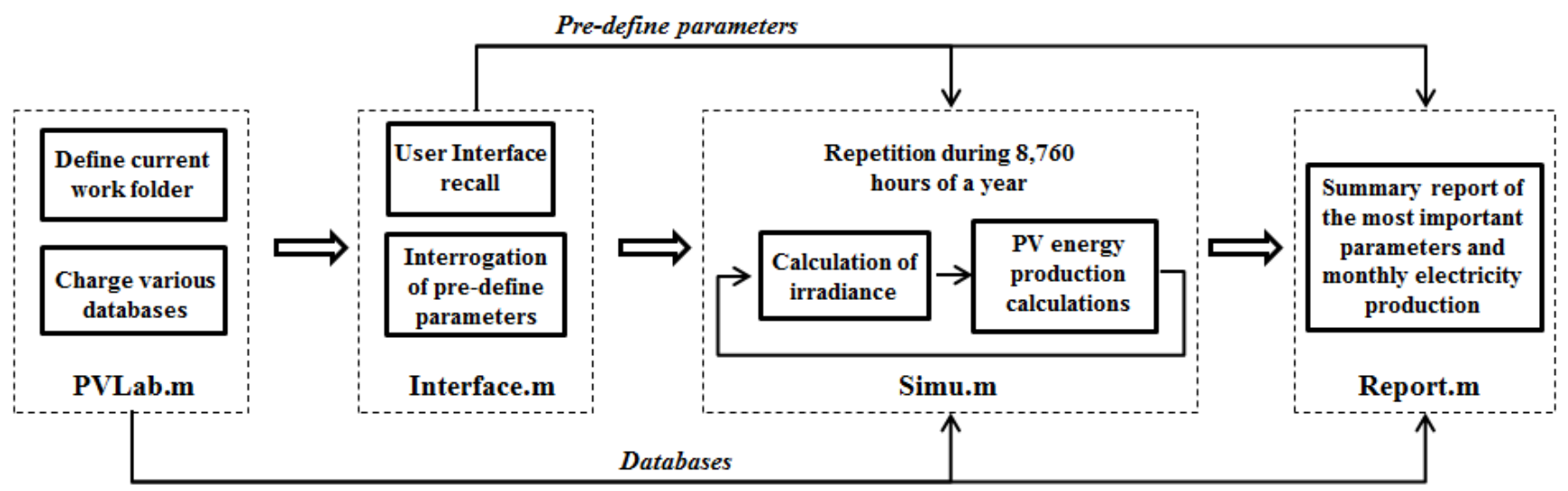

Fig. 1. General architecture of PVLab.

\section{Key models implemented in PVLab}

\section{A. Electrical modeling of the PV module}

As can be seen in Fig. 2, the electrical behavior of a photovoltaic module, based on the equivalent scheme of a PV cell, is modeled as a single-diode electrical circuit including the effect of shunt and serial resistances. It is important to notice that this kind of model is also integrated in PVsyst [7]. It is particularly well-suited to describe Si-crystalline PV modules [8]. A mismatch of only 1 or $2 \%$ on the maximum power point is typically observed between the estimated value from this modeling and the one provided by the manufacturer [9].

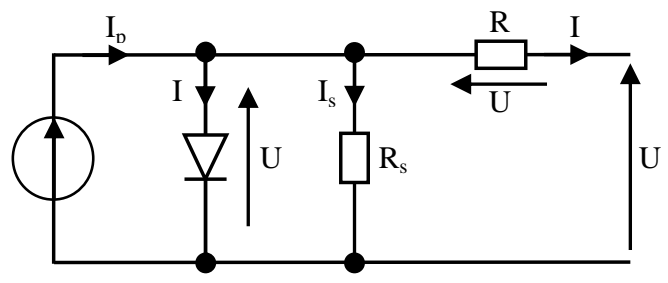

Fig. 2. Single-diode model of a PV cell.

The single-diode model can be described using 3 main equations. The output current flowing the PV module is given in (1).

$I=I_{p h}-\mathrm{I}_{0} \times\left[\mathrm{e}^{\frac{\mathrm{q}}{\mathrm{n} \cdot \gamma \cdot k \cdot\left(U+R_{S} \cdot I\right)}}-1\right]-\frac{U+R_{S} \cdot I}{\mathrm{R}_{\mathrm{sh}}}$

- I: Output current in the PV cell [A].

- U: Output voltage across the PV cell [V].

- $\mathrm{I}_{\mathrm{ph}}$ : Photocurrent (irradiance-dependence) [A].

- $\mathrm{I}_{0}$ : Saturation current (temperature-dependence) [A].

- $\mathrm{q}=1.6 \cdot 10^{-19} \mathrm{C}$.

- n: Number of cells in series.

- $\gamma$ : Diode quality factor $(1 \leq \gamma \leq 2)$.

- $\mathrm{k}=1.38 \cdot 10^{-23} \mathrm{~J}^{-\mathrm{K}^{-1}}$ (Boltzmann's constant).

- T: Effective cell temperature [K].

- $\mathrm{R}_{\mathrm{S}}$ : Serial resistance $[\Omega]$.

- $\mathrm{R}_{\mathrm{sh}}$ : Shunt resistance $[\Omega]$.
From (1), the $I_{p h}$ and $I_{0}$-parameters are the two main unknown variables. The photocurrent $\left(\mathrm{I}_{\mathrm{ph}}\right)$ varies proportionally with the effective irradiance level and the cell temperature. Thus, it is essential to use the conditions defined in the Standard Test Conditions (STC: $\mathrm{G}=1,000 \mathrm{~W} \cdot \mathrm{m}^{-2}, \mathrm{~T}_{\text {cell }}=25^{\circ} \mathrm{C}$, AM1.5). The definition of the photocurrent, as described in (2), is implemented in PVLab.

$I_{p h}(T)=\frac{\mathrm{G}}{\mathrm{G}_{\text {ref }}} \times\left[I_{p h_{-} r e f}+\mu_{I S C} \cdot\left(T-T_{r e f}\right)\right]$

- G: Effective irradiance [W. $\left.\mathrm{m}^{-2}\right]$.

- $G_{\text {ref }}$ : Reference irradiance $\left[W \cdot \mathrm{m}^{-2}\right]$.

- T: Effective cell temperature [K].

- $\mathrm{T}_{\text {ref }}$ : Reference cell temperature [K].

- $\mu_{\text {ISC }}$ : Temperature coefficient of the short circuit current.

Regarding the reverse saturation current ( $\mathrm{I}_{0}$-parameter from (1)), it is strongly dependent on the effective cell temperature as expressed in (3). This third relation is implemented in PVLab.

$I_{0}(T)=\mathrm{I}_{0 \_ \text {ref }} \times\left(\frac{\mathrm{T}}{\mathrm{T}_{\text {ref }}}\right)^{3} \times e^{\frac{q \cdot E_{g}}{\gamma \cdot k} \cdot\left(\frac{1}{T_{\text {ref }}}-\frac{1}{T}\right)}$

- $\mathrm{E}_{\mathrm{g}}$ : Band gap of the semiconductor material, i.e. $1.12 \mathrm{eV}$ for silicon photovoltaic modules.

\section{$B$. Thermal modeling of the PV module}

The three expressions above reveal the great influence of cell temperature to the electrical behavior of the PV module. So, the thermal modeling is necessary to take into consideration the temperature-dependence. The thermal behavior of the PV module is determined by an energy balance between the ambient and the heating effect of PV cells caused by the incident irradiance.

Regarding the two simulation software (i.e. PVLab and PVsyst), the global heat balance approach is used to describe the thermal behavior of a PV module. The cell 
temperature $\left(\mathrm{T}_{\text {cell }}\right)$ is determined using (4).

$$
T_{\text {cell }}=\mathrm{T}_{\mathrm{a}}+\frac{\alpha \cdot \mathrm{G}_{\mathrm{inc}} \cdot(1-\eta)}{\mathrm{H}}
$$

- $\mathrm{T}_{\mathrm{a}}$ : Ambient temperature $[\mathrm{K}]$.

- $\alpha$ : Optical absorption coefficient.

- $\eta$ : Efficiency of the PV module.

- H: Global heat transfer coefficient $\left[\mathrm{W} \cdot \mathrm{m}^{-2} \cdot \mathrm{K}^{-1}\right]$.

From (4), the optical absorption coefficient is usually fixed to 0.9 , which presents the part of incident irradiance absorbed by the tempered glass and the protective resin, which composed a single-glass crystalline silicone PV modules.

A fixed heat transfer coefficient (H-parameter) is used in this model, as in the case of PVsyst. In particular, an empirical value, which is accepted by most of the users (i.e. $29 \mathrm{~W} \cdot \mathrm{m}^{-2} \cdot \mathrm{K}^{-1}$ ), is used. It means that this thermal modeling do not take into account climate conditions such as wind speed or wind direction. As a consequence, a more sophisticated model is needed to better estimate the cell temperature. A newly thermal model has already been implemented in PVLab. Its relevance has already been discussed [10], [11].

\section{Optical model}

The calculation of the effective solar radiation plays an important role in the determination of the electricity production of the PV system. The optical modeling is described in Fig. 3. The outspace irradiance is absorbed and diffused when passes through the atmosphere. At ground, the irradiance is composed of three main parts: the beam, diffuse and albedo components. The Hay's model is applied here to deal with the transposition of the solar irradiance [12]. The beam component is the part received directly from the sun without the diffusion of the atmosphere. It involves a purely geometrical transformation (cosine effect). The calculation of the diffuse component is comparably more complicated. The model proposed by Liu and Jordan, which results form an experimental correlation of the Diffuse/Global ratio by respect to the clearness index, is used here to solve this problem [13]. The global effective irradiance on the PV cell will be equal to the sum of these 3 components.

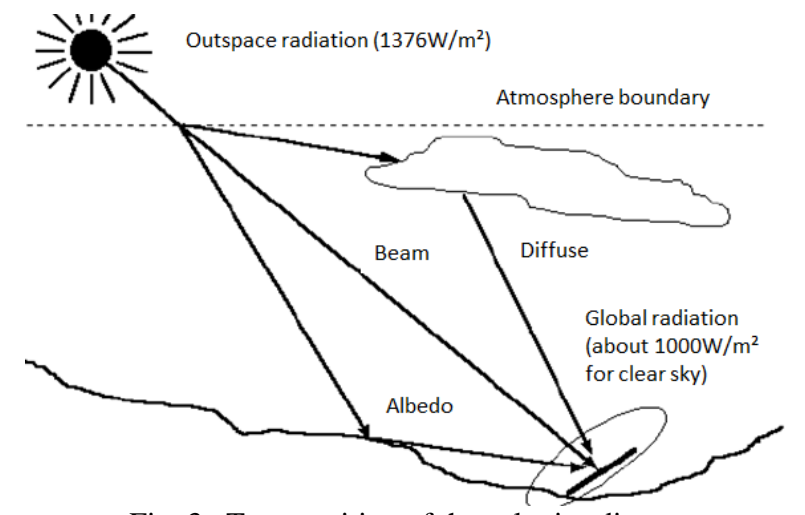

Fig. 3. Transposition of the solar irradiance.

It has to remark that even if the PVsyst and PVLab all apply Hay's model to solve the problem of the irradiance transposition, their final results, determined from the same meteorological databases, are different. The estimation proposed by PVLab may be more pessimistic. Some optical parameters used in these two simulators may be different, but it is hard to point out exactly the difference because the source code of PVsyst is not accessible.

\section{Relevance of PVLab}

\section{A. Case study}

In this section of the paper, a case study is proposed to highlight the relevance of PVLab. The validation is done by calculating the yearly electrical energy production of a PV plant. In particular, a comparison between PVLab results and PVsyst ones, with the same input data, is explained. This case study is carried out for two values of installation power and two values of PV module tilt angle, respectively. The ultimate challenge is to discuss the validity of the various models implemented in PVLab, including the electrical and optical ones.

Regarding the impact of the installation power, two PV plants have been considered with 2 nominal power values equal to $2.6 \mathrm{kWp}$ and $7.9 \mathrm{kWp}$. It means that twelve and thirty-six $220 \mathrm{Wp}$ polycrystalline PV modules (Solar World SW220) are used, respectively. Each gridconnected system is composed of an inverter (SMA Sunny Boy SB3300 and SMA Sunny Mini Central 9000TL dedicated to $2.6 \mathrm{kWp}$ and $7.9 \mathrm{kWp}$ PV installations, respectively) to match the $2 \mathrm{PV}$ power plants described previously. It is important to notice that the same mechanical and electrical characteristics of the PV module and inverters have been considered as input data within the 2 simulators (PVLab and PVsyst). In other words, PVLab and PVsyst use the same databases (same number of points, same values).

Regarding the impact of PV module tilt, two values have been considered: $30^{\circ}$ and $45^{\circ}$. The aim of this study is to get a better understanding of the impact of the optical model implemented in the software.

Regarding the two simulators, the meteorological databases have been unified. In particular, the meteorological data from Tours in France have been implemented within PVLab and PVsyst (from the Meteonorm database).

All these parameters are summed up in Table 1.

Table 1. Main input data implemented with PVLab and PVsyst.

\begin{tabular}{|c|c|c|}
\hline $\begin{array}{c}\text { PV installation nominal power } \\
(\mathrm{kWp})\end{array}$ & 2.6 & 7.9 \\
\hline Number of PV modules & $6 \times 2$ & $6 \times 6$ \\
\hline PV module tilt angle $\left(^{\circ}\right)$ & 30 and 45 & 30 and 45 \\
\hline PV module azimuth $\left({ }^{\circ}\right)$ & 0 (South-facing) \\
\hline PV module quality loss $(\%)$ & 3 \\
\hline Mismatch loss factor $(\%)$ & 2 \\
\hline Soiling loss $(\%)$ & 0 \\
\hline Diode voltage drop $(\mathrm{V})$ & 0.7 \\
\hline Wiring resistance $(\Omega)$ & 0 \\
\hline Albedo coefficient & 0.2 \\
\hline Heat transfer coefficient $\left(\mathrm{W} \cdot \mathrm{m}^{-2} \cdot \mathrm{K}^{-1}\right)$ & 29 \\
\hline Meteorological database & Meteonorm-Tours, \\
& France \\
\hline Near shading & Not applicable \\
\hline
\end{tabular}




\section{B. Discussion}

As mentioned previously, the test matrix is composed of 4 groups based on the nominal power of the PV plants and the tilt angle of the PV modules. The simulation results are summarized in Table 2.

It is important to notice that the error rate between PVLab and PVsyst is lower than 3\%, whatever the case of the test matrix. This error rate is fully acceptable. Another important point is the estimation of the effective irradiance is more pessimistic and prudent with PVLab compared with PVsyst.

When the tilt angle of the PV module is the same, the error rate is constant, whatever the nominal power of the PV plant. The relevance of the electrical model implemented in PVLab is validated.

A contrario, when the value of the PV module tilt angle increases, the error rate between PVLab and PVsyst slightly increases, following the change of the tilt angle. It means that the optical model implemented with each PV simulator presents a few differences.

This study highlights that there are some differences between the electrical and optical models integrated within PVLab and PVsyst. However, the error rate between the two simulators, with the same input data, is acceptable in terms of yearly electrical energy production of a grid-connected PV installation.

Due to the flexibility of MATLAB development environment, all the physical models integrated in PVLab are accessible and changeable. These characteristics provide PVlab a huge advantage for the research and exploitation of PV systems. Additional phenomena, such as the influence of meteorological phenomena (wind speed, wind direction) or the influence of the electrical model (single-diode, 2 diodes), can be taken into consideration however the user wanted.

Table 2. Yearly energy production simulation results - Comparison between PVLab and PVsyst.

\begin{tabular}{|c|c|c|c|c|}
\hline $\begin{array}{c}\text { PV module tilt } \\
\text { angle }\left(^{\circ}\right)\end{array}$ & $\begin{array}{c}\text { PV plant nominal } \\
\text { power }(\mathrm{kWp})\end{array}$ & $\begin{array}{c}\text { Yearly electrical energy } \\
\text { production from PVLab (kWh) }\end{array}$ & $\begin{array}{c}\text { Yearly electrical energy } \\
\text { production from PVsyst (kWh) }\end{array}$ & $\begin{array}{c}\text { Error rate (\%) - PVLab vs. } \\
\text { PVsyst }\end{array}$ \\
\hline 30 & 2.6 & 3,171 & 3,239 & -2.1 \\
\hline 30 & 7.9 & 9,514 & 9,718 & -2.1 \\
\hline 45 & 2.6 & 3,132 & 3,219 & -2.7 \\
\hline 45 & 7.9 & 9,397 & 9,658 & -2.7 \\
\hline
\end{tabular}

\section{Conclusion}

With the development and growing application of the photovoltaic energy, the study and sizing of PV production system is becoming more and more a hot spot. Existing PV simulation software, such as PVsyst, do not allow the users to modify its internal models and databases. Thus, this limits its applications in the field of scientific research.

The GREMAN laboratory has developed an innovative and flexible PV simulation tool, named as "PVLab", based on the MATLAB environment, to answer all the problems described previously. PVLab is composed of 3 key elements: electrical, thermal and optical models.

The electrical model based on the single-diode equivalent scheme is implemented in this new simulator to describe the electrical behavior of PV module. The global heat approach is used to describe its thermal behavior. Finally, the determination of effective incident irradiance is done by the Hay's model.

The validation of PVLab has been carried out by comparing the simulation results (yearly virtual electrical energy production) with PVsyst ones, in the same test conditions (i.e. with the same input data). An error less than $4 \%$ has been quantified. With regard to the more prudent and pessimistic estimation of PVLab, this result is pretty satisfactory.

The flexibility on modifying the internal models and databases of PVLab make it an ideal tool to study and research the PV production system, which is a great advantage compared with PVsyst.

\section{References}

[1] C. Emmott, B. Azzopardi, N. Espinosa, R. Garcia-Valverde, A. Urbina, J. Mutale, F.C. Krebs, J. Nelson, "Economical assessment of solar electricity from organic photovoltaic systems", IET Conference on Renewable Power Generation, February 2011.

[2] M. Takagi, Y. Iwafune, K. Yamaji, H. Yamamoto, K. Okano, R. Hiwatari, T. Ikeya, "Economic Value of PV Energy Storage Using Batteries of Battery-Switch Stations", IEEE Transactions on Sustainable Energy, Volume 4, Issue 1 (2013), pp. 164-173.

[3] Solar Forever - Future of Next Generation, "2012 - A Historic Year for Solar Photovoltaic (PV) Industry”, June 2013.

[4] S. Lüthi, R. Wüstenhagen, "The price of policy riskEmpirical insights from choice experiments with European photovoltaic project developers", Energy Economics, Elsevier, (2012).

[5] P. Karki, B. Adhikary, K. Sherpa, "Comparative study of grid-tied photovoltaic (PV) system in Kathmandu and Berlin using PVsyst", Proceedings of the IEEE International Conference on Sustainable Energy Technologies, 2012, pp. 196-199.

[6] Sun jianping, "An optimum layout scheme for photovoltaic cell arrays using PVSYST", Proceedings of the International Conference on Mechatronic Science, Electric Engineering and Computer, 2011, pp. 243-245. 
[7] PVsyst User's Guide, "Characteristics of a PV Module, model description" University of Geneva, 2010, pp. 111-112.

[8] E.M.G. Rodrigues, R. Melício, V.M.F. Mendes and J.P.S. Catalão, "Simulation of a Solar Cell considering Single-Diode Equivalent Circuit Model", Renewable Energy \& Power Quality Journal No 9 (2011).

[9] M. Taherbaneh, G. Farahani, K. Rahmani, "Evaluation the accuracy of one-diode and two-diode models for a solar panel based open-aire chlimate measurements", Solar Cells-Silicon Wafer-Based Technologies, November, 2011, pp. 202-228.

[10] F. Romary, A. Caldeira, S. Jacques, A. Schellmanns, "Thermal Modelling to Analyze the Effect of Cell Temperature on PV Modules Energy Efficiency", Proceedings of the European conference on power electronics and applications, 2011.

[11] S. Jacques, A. Caldeira, Z. Ren, A. Schellmanns, N. Batut, "Impact of the cell temperature on the energy efficiency of a single glass PV module: thermal modeling in steady-state and validation by experimental data", Renewable Energy and Power Quality Journal No 11 (2013).

[12] S. Ransome, J. Sutterlueti, S. Sellner, "PV technology differences and discrepancies in modelling between simulation programs and measurements", Proceedings of the IEEE Photovoltaic Specialists Conference, 2012, pp. 3061-3066.

[13] T. Khatib, A. Mohamed, K. Sopian, "On the monthly optimum tilt angle of solar panel for five sites in Malaysia", Proceedings of the IEEE Power Engineering and Optimization Conference, 2012, pp. 7-10. 